\title{
Designing interactive scavenger hunt using QR codes
}

\author{
Julia Gressick ${ }^{1}$, Bruce Alan Spitzer ${ }^{2}$, and Kyle Sagarsee ${ }^{3}$ \\ Keywords: educational technology, games in education, $Q R$ codes, quick response codes
}

\section{Framework}

This article describes the use of the Quick Response codes (QR codes) as a way to engage students in an interactive scavenger hunt to review course content prior to an exam.

QR codes (quick response codes) are two-dimensional, camera-readable bar codes that have become popular for allowing smartphones and other camera-equipped, web-connected devices access to web sites, text messages, and application downloads. QR codes are read by a mobile device through the device's camera using an application specifically designed to read the information embedded in the code. QR codes are easily recognizable by their square shape and series of black square/white space patterns. The size of the QR code is largely irrelevant: as long as the device's camera can bring the code into the field of view, the code can be read by the code reader application.

Gaming as a way of learning and reviewing content has become an increasingly popular way to engage students despite objections by adults who see them as not instructional in nature (Swanson, 2014).

\section{Making It Work}

In order to understand the use of QR codes in an interactive game context, it is important know the process for both reading/decoding and creating a $\mathrm{QR}$ code.

\section{QR Code Reader Applications}

A search of e-commerce sites dedicated to iOS and Android operating systems will result in the discovery of a wide variety of free and cost-based applications to read and decode QR codes. There are no discernable differences between various apps and nothing significant is gained by purchasing an app over installing a free app. To use any of the applications, launch the application on a mobile device. The application automatically activates the camera and presents the user a "target" on the screen wherein the QR code graphic should be centered by the user. Once read, the app will take the action inherently embedded in the QR code such as launching a web browser to access an online web site, sending an SMS text message or email message, or downloading and installing an application to the mobile device.

\section{QR Code Generators}

As with QR code reader applications, there are a myriad of web sites that will convert desired actions into readable QR codes. There is nothing significantly different between sites, and most work the same: input information into a form and click a command button to generate

\footnotetext{
${ }_{1}^{1}$ Assistant Professor of Instructional Technology, Indiana University South Bend, jgressic@iusb.edu

${ }^{2}$ Associate Professor of Instructional Technology, Indiana University South Bend, baspitze@iusb.edu

${ }^{3}$ Graduate Student in Education, Indiana University South Bend, ksagarse@iusb.edu
} 
the code. One robust web site for creating free QR codes is QRStuff.com (http://www.qrstuff.com). In addition to a simple QR code creator, QRStuff.com allows for easy creation of QR codes to known web sites (YouTube, Google Maps, Twitter, Facebook, etc.) and other events such as dialing a telephone number, placing a Skype call, and generating an email message. Users have control over the color of the foreground and the output type.

\section{Use of QR Codes in an Interactive Scavenger Hunt}

We developed an educational augmented reality learning game (e.g. Wu \& Wen-Yu Lee, 2012) that leveraged QR codes as a way to engage undergraduate students by getting them up out of their seats, working in small groups, and exploring a new building on campus, all while using their own technology in ways that helped them review and understand the course content. The purpose of this game was to serve as a formative review opportunity beyond a traditional paper and pencil quiz. Our context was an undergraduate foundational educational psychology course at a regional campus of a state university.

The use of technology-based games in education has become a widely recognized and accepted means by which to engage students in the classroom (e.g. Hwang \& Wu, 2012; Burguillo, 2010; \& Kafai, 2006). Moreover, there is considerable theoretical and empirical support of the cognitive benefits of games on student learning outcomes and motivation (i.e. Garris, Ahlers, \& Driskell, 2002; Gee, 2003).

To design our game, we created 20 distinct QR codes and students were divided into eight small groups ranging in size from three to five students. When scanned with a mobile device, each QR code linked students to a multiple-choice question and possible responses created using Google forms (drive.google.com). The questions centered on concepts covered throughout the first two-thirds of the semester. Each of the 20 questions was followed by 4 potential answers teams could choose from. Along with each response, groups were asked to submit their team number for response tracking purposes. Once a team answered a question and their response was submitted, the data were logged in a Google spreadsheet that tracked the time, response, and team number for each attempt. If the question was not answered correctly on the first attempt, multiple attempts were recorded. For each response a team submitted, a prompt directed the team to another door number in the building where they would determine whether or not their response was correct. If they responded correctly, the door they were directed to would have a new QR code for them to scan, which would link to a new question to answer, and so on. If, however, the response was incorrect, there would not be a new code and students would have to return to the previous door, re-scan that QR code, and re-attempt the previous question until they answered correctly and arrived at the door with the next code.

This game was designed to be completed within an hour. Five of the eight teams that participated completed the game, and all eight teams completed at least $75 \%$ of the game. In addition to providing a learning experience that served as an engaging alternative to a traditional quiz, the instructors were provided with a valuable log of how the students responded to the questions, including any incorrect responses and the durations between responses. This afforded the instructional team insight on response trends and highlighted course material that required further focus during instruction. Of the questions that were answered across all teams, 88.3\% were answered correctly on the first submitted response, 9.4\% required a second attempt, and $2.3 \%$ were answered correctly after a third attempt. Since our course enrolled future teachers, the design and implementation of this game not only provided a valuable review opportunity, but also served as an object of reflection for discussing student motivation and as a model of 
innovative instructional design. Students indicated through in-class and online forum reflections that they recognized the potential cognitive benefits of using a game like this in their future classrooms as a way to actively engage students. Our approach provides one example of how to involve students in assessment activities that are collaborative and engaging. Moreover, this approach embraces the Bring Your Own Device (BYOD) movement in educational technology practices (Lai, Khaddage, \& Gerald, 2013) by allowing students to use their personal mobile technology in productive, course-relevant ways.

\section{Future Implications}

Because of the resources we used, the game described here demonstrates the potential for flexible adaptation and use across content areas and educational levels. It provides a way to actively engage learners in collaborative problem solving and further serves to improve rapport among students. Here, we modified a traditional quiz to model a game-based classroom innovation with technology. Integrating this activity into our course instruction provided an opportunity for students to reflect on their problem solving strategies and motivation, both central concepts of the course.

While not a definitive list, some possible adaptations for the strategy can be as follows. This strategy could be adapted to humanities contexts in the form of a library/resource scavenger hunt. Possibilities in the natural sciences include using clues to direct students to natural resources, geological, or botanical examples on campus. An adaption to mathematics could involve student exploration of navigational trigonometry concepts like bearing and course.

As QR codes become more popular and students and faculty both begin using them with more frequency, more strategies for implementing $\mathrm{QR}$ code technology with ubiquitous mobile access devices will become apparent.

\section{References}

Burguillo, J.C. (2010). Using game theory and competition-based learning to stimulate student motivation and performance. Computers \& Education, 55(2), 566-575. doi:

10.1016/j.compedu.2010.02.018

Garris, R., Ahlers, R. \& Driskell, J.E. (2002). Games, Motivation, and Learning: A Research and Practice Model. Simulation \& Gaming, 33(4), 441-467. doi: 10.1177/1046878102238607

Gee, J. (2003). What Video Games Have to Teach Us about Learning and Literacy ( $2^{\text {nd }}$ Ed.). Houndmills, Basingstoke, Hampshire, England; Palgrave Macmillan.

Hwang, GJ \& Wu, PH. (2012). Advancements and trends in digital game-based learning research: a review of publications in selected journals from 2001 to 2010. British Journal of Educational Technology, 43(1). doi: 10.1111/j.1467-8535.2011.01242.x

Kafai, Y. B. (2006). Playing and making games for learning: Instructionist and constructionist perspectives for game studies. Games and Culture, 1(1), 36-40. doi: $10.1177 / 1555412005281767$ 
Gressick, J., Spitzer, B.A., \& Sagarsee, K.

Lai, K-W., Khaddage, F., \& Gerald, K. (2013). Blending student technology experiences in formal and informal learning. Journal of Computer Assisted Learning, 29(5), 414-425. doi: $10.1111 /$ jcal.12030

Swanson, K. (2014). Digital games and learning: A world of opportunities. Tech \& Learning, $34(6), 22$.

Wu, HK, Wen-Yu Lee, S., (2013). Current status, opportunities and challenges of augmented reality in education. Computers and Education, 62, 41-49. doi: 10.1016/j.compedu.2012.10.024 